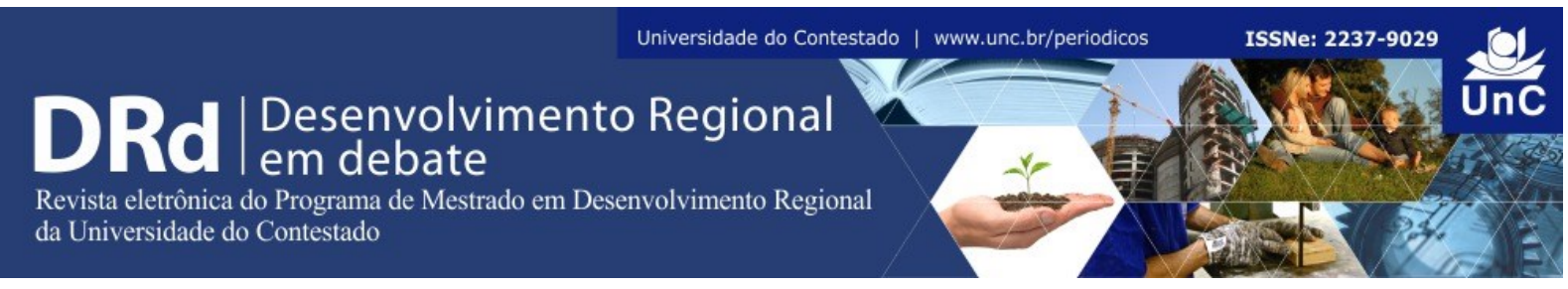

\title{
CONSUMO E ABASTECIMENTO DE FRUTAS E HORTALIÇAS EM ESPAÇOS DE ALIMENTAÇÃO COMERCIAL E COLETIVA
}

Eduardo Gilvan Dutra ${ }^{1}$

Gustavo Pinto da Silva ${ }^{2}$

\begin{abstract}
RESUMO
Este artigo objetiva analisar os potenciais mercados para o abastecimento alimentar através de circuitos curtos, em espaços de alimentação comercial e coletiva em Santiago-RS, Brasil. Problematizam-se as noções de sistemas agroalimentares, estratégias alimentares, circuitos curtos e dinamização econômica. Os procedimentos metodológicos adotados consistiram na realização de estudo de caso, por meio de questionários aplicados, nos meses de novembro e dezembro de 2015 , em pontos de alimentação comercial e coletiva do município, bem como na realização de pesquisas documental e bibliográfica. A análise indica que Santiago possui um público potencial de consumidores que são desconsiderados quando se analisa as oportunidades para iniciativas locais, principalmente em função da urbanização crescente que ocasiona o aumento do número de pessoas que se alimentam fora do domicílio. Existe dependência de alimentos de outras regiões, mesmo que haja emergência de iniciativas locais de comercialização. Verifica-se a inexistência de políticas ou ações regulatórias desses mercados, distanciando, ainda mais, produtores e consumidores de alimentos.
\end{abstract}

Palavra-chave: Alimentação comercial e coletiva. Circuitos comerciais curtos. Abastecimento alimentar. Frutas. Hortaliças.

\section{CONSUMPTION AND SUPPLY OF FRUITS AND VEGETABLES IN COLLECTIVE AND COMMERCIAL FOOD SPACES}

\begin{abstract}
This article aims to analyze the potential food supply markets through short chains, in commercial and collective feeding sites in Santiago - RS, Brazil. The notions of agri-food systems, food strategies, short chains and economic dynamism are problematized. The methodological procedure used was the case study through the application of questionnaires, in the months of November and December 2015, in commercial and collective feeding sites, documentary and bibliographic research. The analysis indicates that Santiago city has a potential market of consumers who are disregarded when opportunities for local initiatives are examined, mainly due to the growing urbanization, which causes the increase in the number of people who eat out. There is dependence on food from other regions, even if there is an

\footnotetext{
${ }^{1}$ Graduando de Ciências Econômicas. Universidade Federal de Santa Maria. Santa Maria. Rio Grande do Sul, Brasil. E-mail: E-mail: eduardodutraeco@gmail.com

${ }^{2}$ Doutor pelo Programa de Pós-Graduação em Extensão Rural da Universidade Federal de Santa Maria. Professor do Colégio Politécnico da Universidade Federal de Santa Maria. Santa Maria. Rio Grande do Sul, Brasil. Email: gustavo.pinto@politecnico.ufsm.br
}

DRd - Desenvolvimento Regional em debate (ISSNe 2237-9029)

v. 7, n. 2, p. 20-38, jul./dez. 2017. 
emergency of local initiatives of commercialization. It is verified the absence of policies or actions regulating these markets, distancing even more the food producers from the consumers.

Key-words: Commercial and collective food. Short Circuits. Food supply. Fruit. Vegetables.

\section{INTRODUÇÃO}

O aumento da população mundial e, especialmente, da urbanizada impôs à agricultura um ritmo diferenciado na produção de alimentos. Com a justificativa da redução de custos e da padronização, o processo natural e as barreiras físicas e biológicas foram convertidos em processos econômicos; e o processamento, o transporte e a logística passaram a ser coordenados por um pequeno número de empresas especializadas, nem sempre com vínculo com a agricultura. Dessa forma, desde a produção até o consumo, os alimentos passam por caminhos complexos, resultado da segmentação e da organização em cadeias, mormente apropriados por distintas formas de capital privado.

As operações que envolvem o fornecimento dos alimentos, na maioria das vezes, são anônimas para o consumidor. O sistema de acreditação de regras e leis do país é quem tem a responsabilidade de formalizar as relações e garantir a segurança em torno da qualidade daquilo que é comercializado. Para o consumidor, todo esse envolvimento antes das gôndolas dos supermercados se torna despercebido, e ele não se dá conta de que esses alimentos, até chegarem a sua mesa podem ter sido produzidos em lugares distantes, submetidos a longas viagens, que podem ter tidos altos gastos energéticos e ambientais, além de terem gerado uma parcela muito baixa de valor agregado para os agricultores de sua região. Para Schmitt (2011, p. 4), esse formato de produção, distribuição e comercialização de alimentos gera o que se pode nominar de "comida de nenhum lugar".

Todavia, mesmo diante do vigor e da robustez desse sistema hegemônico de abastecimento alimentar, as últimas décadas tem se caracterizado pela demonstração de sinais de fragilidade e instabilidade, revelados por meio de uma série de crises alimentares. De acordo com Scarabelot (2012), recentes crises principalmente em países europeus, tais como Bovine Spongiform Encephalopathy (BSE, ou doença da vaca louca), febre aftosa, contaminação química dos alimentos, dioxinas, mutações com organismos geneticamente modificados (OGM), entre outros, comprovam a situação de risco e as fragilidades do sistema agroalimentar moderno, e que comprometem a confiabilidade do consumidor em relação a esse alimento anônimo. Paralelamente, crescem movimentos mundiais em torno de preocupações com uma alimentação mais saudável e comprometida com os aspectos sociais e econômicos de determinadas regiões.

A falta de um planejamento entre a produção e o fornecimento, articulado com a demanda, poderia minimizar perdas para os agricultores, ou então dispor uma constante oferta desses produtos para os consumidores, definido a partir de uma lógica de demanda-consumo (MALUF, 1999). Poucas têm sido as iniciativas em torno de políticas públicas locais, preocupadas com um sistema de abastecimento de alimentos que restabeleça uma relação mais próxima entre quem produz e quem consome. A simples disponibilidade dos alimentos

DRd - Desenvolvimento Regional em debate (ISSNe 2237-9029) 
garante o abastecimento, mas perde o potencial de fortalecer aspectos relacionados à melhora social e econômica das regiões.

O rompimento da relação entre o agricultor e consumidor é ainda mais pronunciado nas alimentações realizadas fora de domicílio, pois os consumidores delegam para outro ente a aquisição dos alimentos e o preparo das refeições. Segundo a Pesquisa de Orçamentos Familiares (POF) 2008-2009, apurados pelo Instituto Brasileiro de Geografia e Estatística (IBGE, 2010), os brasileiros destinam cerca de $30 \%$ da sua renda para alimentação fora do domicílio. Para Maluf (2004, p. 315) "A evolução no perfil do consumo de alimentos no Brasil configura, em termos gerais, um padrão de alimentação em que a refeição fora do domicílio e a utilização de alimentos preparados têm grande ou crescente importância". Conforme Danelon (2012), essas alimentações podem ocorrer tanto em espaços de alimentação coletiva, como comercial. Nos espaços de alimentação coletiva as refeições são destinadas a um público fixo, seja de trabalho (empresas que oferecem vale-refeição ou tem o serviço terceirizado), escolas (através das merendas ou ainda restaurantes universitários), estabelecimentos sociais (casas de repouso, hospital etc.), e outros como forças armadas e entidades religiosas. Os espaços de alimentação comercial tratam com a comercialização de refeições para o público em geral, na forma de restaurantes à la carte, pizzarias, lanchonetes, churrascarias, fast food, entre outros.

Lima Filho et al. (2014) estudaram os impactos das informações nutricionais no comportamento do consumidor de restaurantes, porém sem focar na procedência dos alimentos. O Centro Internacional de Políticas para o Crescimento Inclusivo do Programa das Nações Unidas para o Desenvolvimento demonstrou a importância dos mercados institucionais formados pelo Programa Nacional de Alimentação Escolar (PNAE) e o Programa de Aquisição de Alimentos (PAA) no Brasil, em relação à demanda estruturada de alimentos em pequenos municípios (IPC-IG, 2013). Este trabalho inscreve-se na perspectiva de ampliar o foco de análise sobre os espaços para alimentação coletiva, tais como os vivenciados pelos mercados institucionais, mas também em analisar a alimentação comercial. Desse modo, unificando o estudo sobre os dois espaços de alimentação e, utilizando as frutas e hortaliças como elemento agregador do caso, este trabalho pretende a partir do estudo do município de Santiago (RS) avançar para as discussões relacionadas à importância da procedência em relação ao potencial para a geração de trabalho e renda, principalmente em regiões que possuem histórico de produção familiar. A relevância do trabalho encontra-se na possibilidade de uma melhor articulação entre a oferta e a demanda de frutas e hortaliças, proporcionada, principalmente, pelo reconhecimento da origem dos alimentos. Essa articulação cria o potencial para o fornecimento local de alimentos, a expansão de áreas produtivas, o aumento da circulação de renda, a melhora na oferta de empregos à população rural, e consequentemente a melhora do dinamismo econômico.

Desse modo, o objetivo do trabalho é analisar os potenciais mercados para o abastecimento alimentar pelos circuitos curtos de comercialização, em espaços de alimentação comercial e coletiva em Santiago (RS, Brasil). Ao mesmo tempo espera-se responder os seguintes objetivos específicos: a) identificar o perfil ocupacional do consumidor do município; b) verificar a expressividade de refeições oferecidas em espaços de alimentação comercial e coletiva; e c) identificar e dimensionar a procedência das frutas e hortaliças que sustentam os espaços de alimentação comercial e coletiva. Para se obter resultados a pesquisa apresentada neste texto tem um caráter exploratório mais geral, por meio de análise de documentos e pesquisa bibliográfica, mas também é descritiva, devido à aplicação de 
questionários semiestruturados às pessoas nos estabelecimentos de alimentação comercial e coletiva do município de Santiago. Além disso, acredita-se que se avança em relação a outros estudos, pois este busca evidências em espaços de alimentação coletiva pouco estudados, como os hospitais e os refeitórios dos quartéis das Forças Armadas, que por força do decreto federal n. ${ }^{\circ} 8.473$ de junho de 2015 , passam a adquirir um percentual mínimo de $30 \%$ dos alimentos diretamente dos agricultores familiares.

O texto a seguir está organizado em quatro seções além desta introdução: a revisão bibliográfica, com o objetivo de localizar o artigo em relação à abordagem teórica; os procedimentos metodológicos; os resultados com os principais aspectos do campo empírico, buscando analisá-los; e, por último, pontuam-se as considerações mais relevantes do estudo.

\section{REVISÃO BIBLIOGRÁFICA}

O sistema alimentar vigente está marcado pela compra de alimentos pelos atacadistas, pela sujeição a longas viagens e, posteriormente, pelo armazenamento até a comercialização. A realidade desse sistema está pautada numa organização onde a compra e a distribuição pelas grandes redes de supermercados baseiam-se em aquisições centralizadas, o que reduz o número de fornecedores, aumentando cada vez mais o volume do pedido, demandando maior gasto com transporte dos produtos, estocagem e armazenamento (GREEN; SCHALLER, 1996). O número de pessoas que fazem suas refeições fora de casa também é progressivo, como demonstram alguns estudos publicados por ABIA (2016), ABRASEL (2016) e IBGE (2011).

Segundo Perez-Cassarino et al. (2013), a dinâmica produtiva agropecuária e a desestruturação dos sistemas locais de produção estão diretamente relacionados à liberalização da economia, à abertura e incentivo às exportações e à constante oferta de produtos de procedência internacional. No sistema agroalimentar, tais situações são retratadas quando se encontram nos supermercados, por exemplo, pêssegos, ameixas, maçãs, cebolas ou outras frutas e hortaliças provenientes de outros países. Para Wiskerke (2009) os alimentos são produzidos em "pontos quentes" para depois serem distribuídos para "pontos frios". Os pontos quentes são geralmente receptores de valores monetários os quais fomentam seu desenvolvimento local, criam matrizes agroalimentares e consequentemente trazem melhor qualidade de vida para os que habitam no seu entorno. Em contrapartida, os pontos frios são aqueles que demandam os alimentos de outros lugares, despendem valores monetários que poderiam ser realocados na própria comunidade. Resultado disso são algumas economias crescentes, cada vez mais concentradas (pontos quentes), e localidades dependentes de alimentos, cada vez mais sujeitas à marginalização e recessões econômicas (pontos frios).

As mudanças relativas à centralização e concentração das cadeias produtivas beneficiam os circuitos longos, baseados no deslocamento de produtos e matérias primas e na desconexão entre produção e consumo. Isso gera o pleno distanciamento social e cultural entre agricultores e consumidores, e, para os últimos, o total fetiche sobre aquilo que é consumido (TRICHES, 2010). Nesse sentido, 
O avanço das grandes redes supermercadistas e seu intenso processo de concentração corporativa levam a um equivalente poder de definição dos padrões de produção e consumo, respectivamente, aos agricultores e consumidores, por dominarem a etapa final do processo alimentar, a comercialização direta ao consumidor (PEREZ-CASSARINO et al., 2013, p. 7).

Nos últimos anos em função da forma pelas quais as relações de comercialização acontecem, cada vez mais tem se distanciado o contato entre quem produz o alimento no campo e quem os consome na cidade (WISKERKE, 2009). Resultado desse distanciamento é que, para compensar a falta de contato direto e de confiança pessoal que era possível em outros tempos, o consumidor precisa acreditar nos crescentes níveis de formalização, regulamentos detalhados e sistemas de qualidade. Por outro lado, a elevada complexidade causada por um crescente número de marcas, rótulos e selos nas gôndolas dos supermercados, vem causando confusão quanto aos seus significados e a credibilidade que são merecedores entre os consumidores.

Paralelamente, o planejamento do abastecimento alimentar foi aos poucos esquecido ou relegado para as regras do mercado, para que se enquadrasse na livre concorrência. $\mathrm{O}$ fato de o sistema estar sob a tutela do mercado pode ser atribuído à globalização do sistema de distribuição alimentar, que fez com que os sistemas de abastecimento se tornassem mais concentrados do que eram no passado, mas também por questões dos próprios fluxos demográficos e de urbanização, dado que grande parte da população mundial tem se concentrado em cidades e metrópoles. Para Morgan e Sonnino (2010), entre as possibilidades de mudança, o Estado tem papel fundamental, já que tem a capacidade de utilizar o seu poder de regulação e de decisão sobre alocação de recursos e de protagonista no abastecimento alimentar para promover mudanças no comportamento da sociedade. Os autores destacam como exemplo desse tipo de ação as políticas de alimentação escolar, em voga em vários países do mundo.

No Brasil alguns mercados institucionais tem se revelado como uma iniciativa importante no que tange a aquisição de alimentos, dentre eles o próprio mercado da alimentação escolar, mas também o de Aquisição de Alimentos (PAA). A aquisição dos alimentos para as forças armadas por meio do PAA oferece uma perspectiva interessante para os sistemas locais de produção e consumo, na medida em que forma uma demanda agregada considerável. Segundo Vidal et al. (2011), a alimentação fornecida para homens das forças armadas deve seguir um padrão de qualidade higiênico-sanitária e nutricional, junto com boas práticas em segurança alimentar, com fins de possibilitar o melhor desempenho possível, bem como a manutenção da saúde.

Para Pothukuchi (1999), o sistema alimentar pode estar despercebido aos olhos dos cidadãos, pois esses acreditam que o funcionamento seja perfeito, esquecendo que nem todos tem acesso aos alimentos básicos para suprir suas necessidades nutricionais; os alimentos não recebem, pelos urbanos, a mesma magnitude de importância tais como habitação, crimes, transporte e outros assuntos das cidades; e poucos são os que têm conhecimento de quanto viajam os alimentos (food miles) até alcançar o consumidor final. De acordo com Favero $(2005$, p. 3) a questão do planejamento alimentar é estratégica principalmente no que tange a segurança alimentar e não pode ser esquecida, mesmo diante das "[...] mudanças ocorridas no âmbito da produção e no sistema de abastecimento com a chegada de novos atores, como as grandes redes de distribuição e de varejo". 
A evidência de organização e novos realinhamentos em torno do fornecimento de alimentos apresentam condições de ser um instrumento de desenvolvimento das comunidades produtoras, principalmente para a agricultura familiar, que historicamente viu suas atividades serem preteridas, em relação aquelas de cunho patronal e tomadas como mais importantes para o país, como as atividades de exportação. Sousa (2006) salienta que a alimentação dever ser redimensionada, de um lado pela necessidade de mudanças de hábitos, e de outro por uma sociedade que clama pela substituição de uma alimentação não tão saudável, para uma mais saudável. Assim, pode-se também reafirmar as identidades locais das populações ou comunidades, no que tange ao comportamento alimentar e costumes.

Esse processo de mudança busca a diversificação e valorização da produção local. $\mathrm{Na}$ literatura internacional é conhecido como quality turn, e, segundo Schneider et al. (2015), consiste em um movimento em busca da valorização de produtos alimentares de qualidade, diferenciada por consumidores cada vez mais reflexivos e informados. Ao mesmo tempo, esse referencial teórico encontra-se preocupado em prezar por formas autônomas de produção e comercialização, assim voltando-se para práticas alimentares mais relacionadas ao local e que sejam capazes de incorporar valor às regiões que foram alijadas pelo modelo produtivista, generalizador e globalizante (DUPUIS; GOODMAM, 2005). É importante lembrar que cada lugar apresenta suas próprias dinâmicas de provimento alimentar e de como esses mercados alimentares funcionam. Para Thies e Conterato (2017), referindo-se às dinâmicas de desenvolvimento rural e aos processos de transformação na agricultura, é fundamental estudar o modo como os agricultores se inserem, constroem e se relacionam com os mercados. Esse trabalho está buscando fazer essa análise, mas a partir de como os mercados de alimentação comercial e coletiva se formaram, como atualmente encontram-se constituídos e de que forma os agricultores se apropriam deles. Até por que ele pode possuir práticas alimentares mais ou menos autônomas a partir de um dado lugar.

Diante do contingente de pessoas que fazem suas refeições fora do domicílio, e no propósito de minimizar a quantidade de alimentos que veem de fora para o preparo dessas refeições, é que este trabalho ganha relevância. Na medida em que essa demanda possa ser oferecida por meio das expressões de abastecimento e mercados construídos localmente, certamente aumenta o potencial de impacto das formas de abastecimento para o desenvolvimento territorial. Para Dallabrida (2015, p. 235), desenvolvimento territorial é:

[...] um processo de mudança continuada, situado histórica e territorialmente, integrado em dinâmicas intraterritoriais, supraterritoriais e globais, sustentado na potenciação dos recursos e ativos (materiais e imateriais, genéricos e específicos) existentes no local, com vistas à dinamização socioeconômica e à melhoria da qualidade de vida da sua população.

Do ponto de vista do desenvolvimento territorial tem que se considerar que a agricultura não é a única atividade capaz de dinamizar economicamente uma região. Porém, em regiões onde existe uma identidade sociocultural historicamente construída, vinculada principalmente com a agricultura familiar, que são a maior parte dos estabelecimentos rurais brasileiros, também não se pode deixar de considerar essa possibilidade. Segundo Guanziroli (2008), é a própria realidade do local, por meio do diagnóstico dos elementos estruturados de cada região, que define o peso de cada atividade em seu desenvolvimento, e não o planejador de forma antecipada. Por essa razão, aprofundar o conhecimento da realidade local é fundamental para o fortalecimento de sistemas agroalimentares mais sustentáveis, uma vez 
que, para superar a pobreza na agricultura, a produção de alimentos pode se apresentar como uma contribuição estratégica.

\section{METODOLOGIA}

Para esta pesquisa foi utilizado o caso do município de Santiago, localizado na Região Central do Estado do Rio Grande do Sul, Brasil. O município apresentou uma população de 49.071 habitantes segundo o Censo Demográfico de 2010 (IBGE, 2016). A expressividade da população urbana e sua vinculação com outras formas de trabalho e vínculos ocupacionais, quando em comparação com outros municípios da região, justifica a escolha desse caso para ser estudado. Do mesmo modo, o município tem uma forte ligação com a produção rural, especialmente advindo de uma região de colonização italiana, que configura, até o presente, a existência de sistemas de produção típicos da agricultura familiar (SILVA, 2016). Este público tem sido colocado diante de uma prova de resistência, enfrentando diretamente as transformações econômicas promovidas pela globalização e que os incluem em graves problemas sociais.

A economia de Santiago é oriunda basicamente da prestação de serviços e da produção de commodities, características comuns quando estudados municípios da Metade Sul do Rio Grande do Sul. Santiago é uma referência educacional, visto que apresenta uma universidade com cursos de graduação e pós-graduação, quatro polos universitários da modalidade educação à distância $(\mathrm{EAD})$, cursos técnicos profissionalizantes, tanto de natureza privada quanto pública, e também escolas de ensino fundamental e médio. Os principais empregadores são as unidades militares do Exército Brasileiro, o comércio local, as instituições de ensino, o Hospital de Caridade e a Prefeitura Municipal.

A pesquisa teve um caráter exploratório, buscando informações que proporcionassem familiaridade em relação ao objeto de estudo, principalmente em conhecer melhor como ocorre a formação do efetivo de consumidores de Santiago, o tamanho do consumo e a procedência de frutas e hortaliças para esses espaços de alimentação.

Por limitação de tempo e recursos para a pesquisa foram aplicados questionários semiestruturados em uma amostra de estabelecimentos de alimentação especialmente onde se atestou refeições com maior diversidade e regularidade de frutas e hortaliças. A amostra em relação a alimentos de espaços de alimentação comercial foi de 11 restaurantes e similares, quatro churrascarias e duas lanchonetes. Segundo informações da Secretaria de Gestão da Prefeitura Municipal de Santiago encontram-se registrados para funcionamento no município os seguintes quantitativos de estabelecimento comerciais: 07 restaurantes, 12 restaurantes e similares, 58 lanchonetes, 29 estabelecimentos de fornecimentos de alimentos preparados para consumo domiciliar e 16 estabelecimentos de serviços ambulantes de alimentação (MARTINS, 2015). Os estabelecimentos de alimentação coletiva foram as 5 unidades militares do Exército Brasileiro e o Hospital de Caridade de Santiago. Também foi realizada pesquisa documental e bibliográfica em livros e documentos, de modo a compreender como se formou o efetivo de consumidores do município, pois certamente os processos passados também incidem sobre o momento atual. A pesquisa de campo foi desenvolvida entre os meses de novembro e dezembro de 2015. 
O roteiro de pesquisa foi composto por questões quantitativas e qualitativas. Os principais aspectos abordados foram: número de refeições servidas; consumo e origem das frutas e hortaliças; quantidade gasta em dinheiro para aquisição das matérias-primas; e possibilidade de compra local. A análise dos dados foi realizada por meio de medidas de proporcionalidade e de interpretação de resultados, buscando o entendimento em torno das características do consumidor dos espaços de alimentação comercial e coletiva de Santiago, para depois adentrar no detalhamento sobre as formas de provisão alimentar. Por fim, uniramse os dados para estabelecer seus sentidos, e de estes se vincularem com os objetivos da pesquisa, visando a construção deste artigo.

\section{RESULTADOS E DISCUSSÕES}

Com o intuito de responder aos objetivos do trabalho na temática do abastecimento, é que este tópico será destinado. Para tanto, segue-se como premissa de que em circuitos curtos não se vende apenas produtos e serviços oriundos do lugar, mas sim toda uma contribuição de um arranjo envolvido, constituída por atores privados, públicos, mas também a conexão geográfica, formada por paisagem, clima, dentre outros. Ou seja, estamos tratando do próprio território como produto a ser vendido, constituindo ele próprio a oferta compósita, como bem conceitua Pecqueur (2009). Assim, o primeiro tópico desta seção discute os aspectos da formação do efetivo de consumidores em Santiago; o segundo, o quão economicamente significa essa alimentação em espaços comerciais e coletivos; e, por fim, serão destinados alguns parágrafos para mapear e discutir a origem e procedência das frutas e hortaliças oferecidos nesses espaços.

\subsection{ASPECTOS DA FORMAÇÃO DO EFETIVO DE CONSUMIDORES EM SANTIAGO}

A formação da população urbana de Santiago teve aumento significativo nas últimas décadas, conforme pode ser verificado na tabela 01 . Esse incremento é concomitante ao êxodo rural advindo principalmente do processo da modernização da agricultura pela Revolução Verde, ocorrido a partir da década de 1960, já que a população urbana praticamente triplicou em quarenta anos. Paralelo ao aumento da Santiago também aconteceu o desenvolvimento de outros setores econômicos do município.

O deslocamento de corporações militares para Santiago iniciou em 1922 e foi um dos indutores de crescimento populacional e formador do efetivo de consumidores que atualmente se alimentam fora do domicílio. A primeira unidade militar foi o Primeiro Regimento de Cavalaria Independente, antes estabelecido nos municípios de Santana do Livramento, São Nicolau e Porto Alegre, e, ainda em 1946, deslocado para Itaqui. Esse deslocamento de unidades militares foi típico da época, pois se vivia o denominado "período entre guerras", que corresponde ao fim da Primeira Guerra Mundial (1918), e início da Segunda Guerra Mundial (1939). O que justifica esse processo era instalar as corporações em locais mais estratégicos, pois unidades de cavalaria mecanizada eram fundamentais para a defesa terrestre 
do território nacional. Somente com o Decreto ${ }^{\circ}$ 01-RES, de 11 de novembro de 1971, é que a corporação retorna a Santiago, agora sede da $1^{\text {a }}$ Divisão da Cavalaria do Estado, hoje $1^{\mathrm{a}}$ Brigada da Cavalaria Mecanizada (SIMÕES, 1989).

A década de 1940 até os anos 1970 trataram-se de outro período de migração de pessoas para Santiago, pois novamente chegaram militares para constituírem outras unidades, sendo que traziam suas famílias das mais variadas regiões do país (SIMÕES, 1989). Iniciando o processo, naquela década se instala no município a $1^{\mathrm{a}}$ Companhia Montada de Transmissões, quando passou a ser denominada de $11^{\mathrm{a}}$ Companhia de Telecomunicações em 1953, como é conhecida atualmente. Ainda nos anos 1940, com a finalidade de constituir-se como unidade de Apoio a Combates, se instala na cidade o 19 Grupo de Artilharia de Campanha. Mais tarde, em 1943, com intuito de prestar serviços médico-hospitalares às organizações militares, cria-se o Hospital de Guarnição de Santiago, ligado a $1^{\text {a }}$ Divisão de Cavalaria, atual $1^{\circ}$ Brigada de Cavalaria Mecanizada (HGuSt, 2016). Também incrementando o contingente militar local, na década de 1970, foi transferido de Santo Ângelo (RS) o $4^{\circ}$ Regimento de Cavalaria, que depois de reformulado em 1974 passa a funcionar como $9^{\circ}$ Batalhão Logístico (SIMÕES, 1989).

Assim, o município ficou constituído com cinco unidades militares, o que soma 1200 militares na ativa. Além desse aumento direto da população urbana, também houve um efeito indireto, já que aumentou a necessidade de outros tipos de serviços, e que fortalecessem processos de dinamismo econômico. Para Constantino (1984), por incrementar o número de habitantes, fomentar o mercado consumidor e ser difusor de outras culturas, o Exército Brasileiro foi um dos mais importantes agentes transformadores de Santiago.

A segunda ocorrência importante para o aumento do contingente urbano ocorreu no final da década de 1930, devido à construção da Estação Férrea "São Thiago", que liga o município a vários outros pontos do estado (CONSTANTINO, 1984). A instalação da linha férrea trouxe mudanças aos aspectos sociais, econômicos, políticos, culturais e até religiosos, e a promoção de uma série de vagas de trabalho. No ramo de frutas e hortaliças, destaca-se a "Fruteira do Lolote", inaugurada em 1952, que trazia esses alimentos desde Porto Alegre por meio dessa estrada férrea.

Mais tarde, a criação da Universidade Regional Integrada Campus Santiago também foi um fator importante na constituição desse consumidor local. A universidade foi fundada na década de 1990 com o objetivo de atender a comunidade regional, especialmente os municípios limítrofes. Conta com um Campus de ensino superior e também com uma escola de Educação Básica, reunindo, atualmente, 260 servidores, entre técnico administrativos e docentes, e 2.218 estudantes, entre graduação e pós-graduação (MORO, 2015). 
Tabela 01 - População total, população urbana e crescimento populacional urbano do município de Santiago entre as décadas de 1950 e 2010

\begin{tabular}{ccccc}
\hline Ano & População Total (n. $\left.{ }^{\circ}\right)$ & $\begin{array}{c}\text { População Urbana } \\
\left(\text { n. }{ }^{\circ}\right)\end{array}$ & $\begin{array}{c}\text { Crescimento } \\
\text { População Urbana (\%) }\end{array}$ & $\begin{array}{c}\text { populacional urbano } \\
(\%)\end{array}$ \\
\hline 1950 & 31.300 & 9.992 & $31,60 \%$ & - \\
1960 & 34.420 & 15.833 & $45,90 \%$ & $36,89 \%$ \\
1970 & 41.054 & 22.043 & $53,60 \%$ & $28,17 \%$ \\
1980 & 46.627 & 30.394 & $65,10 \%$ & $27,48 \%$ \\
1990 & 51.755 & 39.645 & $76,60 \%$ & $23,33 \%$ \\
2000 & 52.138 & 44.455 & $89,00 \%$ & $10,82 \%$ \\
$\mathbf{2 0 1 0}$ & 49.071 & 44.390 & $90,40 \%$ & $-0,15 \%$ \\
\hline
\end{tabular}

Fonte: IBGE (2015)

Segundo o Censo Demográfico de 2010 a população economicamente ativa de Santiago era de 23.988 habitantes (IBGE, 2016). Nessa perspectiva, o setor terciário é o responsável por empregar maior quantidade de pessoas com um montante de 16.827 $(70,15 \%)$, seguido do setor primário com $3.746(15,61 \%)$, e por fim do setor secundário com 3.415 (14,24\%). A urbanização e o aumento da população trouxeram consigo uma série de empresas de comercialização de bens e mercadorias, prestadores de serviços, profissionais liberais, dentre outros, os quais contribuem na formação de um agregado de consumidores dispostos a comprar. Segundo Veiga (2002), a geração de uma demanda agregada por produtos e serviços seria uma forma de promover a economia local dos territórios, fortalecendo uma revalorização espacial da economia.

A outra forma de ocupação predominante advém das atividades da agricultura. $\mathrm{O}$ município destaca-se como um grande produtor agropecuário, tanto na produção pecuária, com um expressivo número de animais bovinos e ovinos, 200.000 e 80.000 cabeças, respectivamente, como também na produção agrícola, possuindo 34.000 hectares cultivados de soja. $\mathrm{O}$ setor industrial relacionado à transformação também é significativo, pois ocupa 3.415 pessoas (IBGE, 2016). A produção industrial por mais que não seja tradicional na região vem ganhando espaço, na medida em que a indústria da construção civil se beneficia de investimentos a partir da valorização dos produtos do setor primário, especialmente a soja.

Essas informações permitem localizar o potencial consumidor dos espaços de alimentação comercial e coletiva no município de Santiago. Constituiu-se uma demanda agregada que se torna o viabilizador para a concentração espacial de operações em torno de um sistema de produção e consumo de base local-territorial. Para Sumpsi (2007), núcleos urbanos intermediários permitem aproveitar as inter-relações entre o meio mais rural e o urbano, como motor de desenvolvimento. Já quando se tratam de zonas rurais sem núcleo urbano intermediário e localizado distante dos centros urbanos, geograficamente separadas, as possibilidades de desenvolvimento ficam menores. Muitas vezes esses números deixam de ser analisados, privando-se dessas potencialidades como fator promotor de oportunidades de geração de trabalho e renda para o município. 


\subsection{EXPRESSIVIDADE ECONÔMICA DA ALIMENTAÇÃO COMERCIAL E COLETIVA EM SANTIAGO}

No modo de vida contemporâneo, a ação de se alimentar fora do domicílio está relacionada a aspectos pessoais, como a preferência por um prato específico, como por fatores interpessoais, como a falta de tempo para preparação da refeição em casa. Segundo a Associação Brasileira das Indústrias da Alimentação (ABIA, 2016), alguns dos fatores que fizeram com que aumentasse a demanda por alimentos fora do domicílio são: o aumento da população nas classes A, B e C, o que gerou mais de 60 milhões de novos consumidores; o aumento da massa salarial, o que aumentou a renda disponível entre os brasileiros; e as mudanças no modo de viver da população, a qual busca maior comodidade e praticidade, alimentação saudável, bem como a redução do tempo disponível da mulher para o preparo das refeições em casa devido sua inserção no mercado de trabalho.

Segundo dados disponibilizados pela Associação Brasileira de Bares e Restaurantes (ABRASEL, 2016), este mercado é formado por um milhão de empresas distribuídas entre restaurantes, bares e atividades do setor (incluindo restaurantes e pizzarias que comercializam alimentos por quilo e à la carte). Isso representa aproximadamente $2,4 \%$ do PIB brasileiro. No ano de 2008 o faturamento desse setor aproximou-se dos 50 bilhões de reais. A Pesquisa de Orçamento Familiar (POF) corrobora com essas informações, afirmando que nos últimos anos houve um aumento significativo do número de refeições servidas fora do domicílio no Brasil. A POF 2008-2009 identificou que os brasileiros gastavam em torno de $31 \%$ da sua renda com alimentação fora do domicílio, contra 24\% nos anos de 2002-2003. Ainda segundo a POF 2008-2009, os brasileiros consomem cerca de $80 \mathrm{~g}$ diários entre frutas e hortaliças, sendo aproximadamente $70 \mathrm{~g}$ pelos homens, e $90 \mathrm{~g}$ pelas mulheres (IBGE, 2011). Conforme apresentado no gráfico a seguir, nota-se que no decorrer entre 2003 para 2009 aumentou significativamente o gasto com a alimentação fora do lar e a região Sudeste foi a que mais aumentou suas despesas em comparação com as demais regiões.

Gráfico 1 - Percentual das despesas monetária e não monetária média mensal familiar com alimentação fora de casa, segundo as Grandes Regiões - período 2002-2009

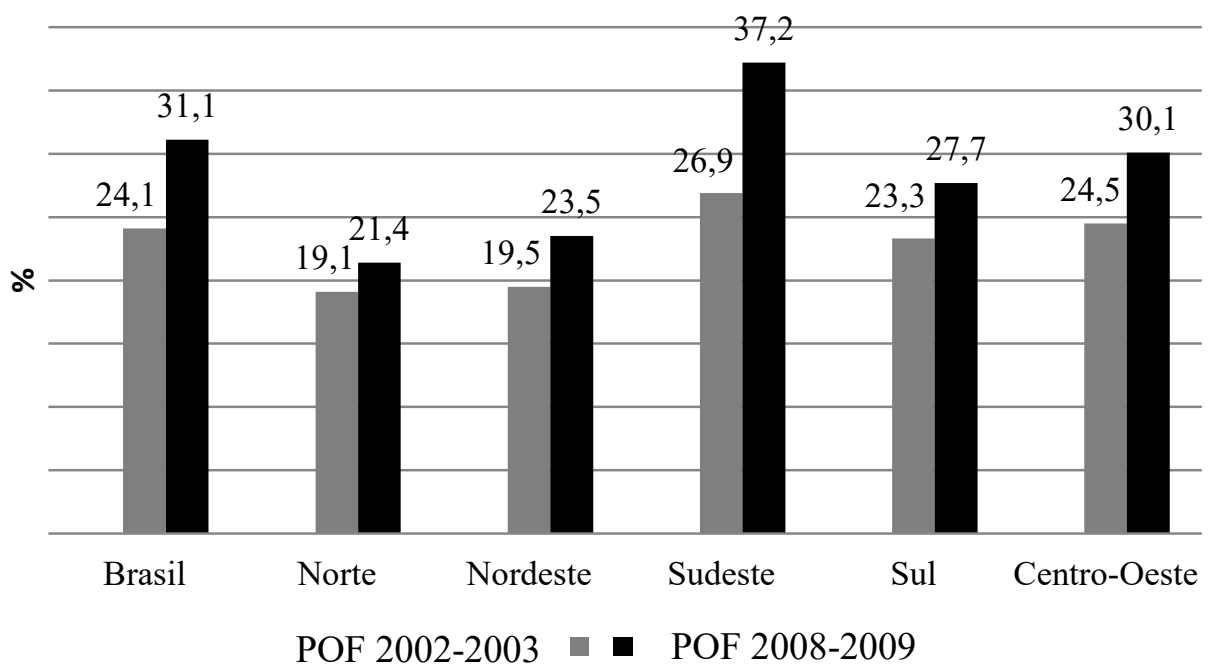

Fonte: Diretoria de Pesquisas, Coordenação de Trabalho e Rendimento, Pesquisas de Orçamentos Familiares 2002-2003; 2008-2009, IBGE (2010)

DRd - Desenvolvimento Regional em debate (ISSNe 2237-9029) 
As mudanças socioeconômicas e demográficas que ocorreram no Brasil nas últimas décadas, e que provocam alterações nos hábitos alimentares, não são diferentes em Santiago. Pela análise dos dados constatou-se que são fornecidas diariamente 2.100 refeições em restaurantes, churrascarias e lanchonetes do município. Ao considerar que cada refeição corresponda a uma pessoa, $8,75 \%$ da população economicamente ativa ou $4,73 \%$ da população urbana do município recorre a espaços de alimentação comercial para realizar suas refeições. Segundo Jornal Expresso Ilustrado (2015), o preço médio do quilograma das refeições servidas em espaços de alimentação comercial de Santiago (RS) está em torno de R\$ 32,40 . Observando que cada pessoa que frequenta esses espaços constitua uma refeição com aproximadamente $500 \mathrm{~g}$ de alimento, são gastos diariamente em torno de $\mathrm{R} \$ 34.020,00 \mathrm{com}$ alimentação em restaurantes, lanchonetes e afins.

Nos espaços de alimentação coletiva foram constatadas 1.515 refeições diárias fornecidas pelas corporações militares e 465 pelo Hospital de Caridade de Santiago. Reunindo os números das refeições realizadas tanto nos espaços de alimentação comercial como coletiva em Santiago, pode-se afirmar que aproximadamente 4.080 pessoas ou $17 \%$ da população economicamente ativa realizam diariamente as refeições fora do domicílio.

Estudos recentes realizados por Claro, Levy e Bandoni (2009), baseados na POF 20022003, com base em variáveis sociodemográficas e econômicas, apontaram que $21 \%$ dos gastos totais com alimentação das famílias são oriundas com alimentações realizadas fora do lar. Os autores acrescentam que essa participação aumenta na medida em que se aumenta a renda, bem como a proximidade das capitais do estado.

Bezerra et al. (2013), utilizando o Inquérito Nacional de Alimentação (INA) e também dados da POF (2008-2009), reportou que numa amostra de 34.003 indivíduos acima de dez anos, $40 \%$ dos entrevistados realizam alguma refeição fora do domicílio no transcorrer de 24 horas. A pesquisa também apontou que o percentual de indivíduos com consumo de alimentos fora do domicílio diminuiu com a idade e aumentou com a renda em todas as regiões brasileiras, entretanto os homens tem maior representatividade que as mulheres nessa forma de consumo, bem como os residentes das áreas urbanas quando comparados aos da área rural.

No que tange a alimentação fora do casa em países desenvolvidos, verificou-se que esse processo já se consolidou a mais tempo. Nos Estados Unidos, por exemplo, segundo Harnack, Jeffery e Boutelle (2000), a participação das despesas com alimentação fora de casa passou de $20 \%$ na década de 1970 , para $38 \%$ do gasto total com alimentação nos anos de 1990. Isso remete pensar que agora no século XXI esse tipo de gasto é ainda maior, o que denota num novo modo de vida, onde as refeições não mais são, em grande parte, daquele modo tradicional realizado em suas residências, mas sim o que busca a praticidade e economia de tempo, alimentando-se em pontos de alimentação comercial e/ou então coletiva.

Fazendo uma aproximação de um valor gasto mensal com frutas e hortaliças tanto nos espaços de alimentação comercial como coletiva, identificou-se que são aproximadamente R \$ $38.000,00$ nos restaurantes, churrascarias e lanchonetes; R\$ 13.380,00 pelas unidades militares; e R \$ 5.840,00 pelo Hospital de Caridade de Santiago. De maneira agregada são R\$ $57.220,00$ gastos mensalmente entre pontos de alimentação comercial e coletiva. Parte desses valores são gastos com alimentos provenientes de agricultores locais e outra parte de intermediários. 
Wilkinson (2004), em seus estudos, reconhece a fragilização da participação de agricultores locais no que tange ao abastecimento alimentar dos mercados localizados no Brasil e discorre a história econômica a fim de explicar tal fenômeno. Segundo o autor, após a ineficiente tentativa da política macroeconômica de substituição de importações adotada pelos governos brasileiros e demais governos de países latino-americanos nas décadas de 1960 e 70 , junto à crise dos anos 1980, fez com que esses remodelassem seus sistemas de governança internos e externos devido à pressão sofrida oriunda dos organismos financeiros internacionais. No Brasil em específico, isso resultou na retirada do governo em relação aos assuntos dos mercados nacionais, principalmente aqueles que tangem controles diretos de preços, compras, regulações de oferta e demanda, além de políticas setoriais localizadas. Assim, se abriram os mercados ao comércio internacional e passou a ocorrer menor protecionismo tarifário, o que resultou na entrada de alimentos por meio de importações, como se pode atestar através de alimentos como cebola, ameixa e maçã proveniente dos países vizinhos.

Ademais, Reardon et al. (2003) atribuem a saída de divisas em circuitos localizados ao avanço dos supermercados nos países da América Latina que chegam com estratégias de regionalização. Esse processo busca o domínio da grande distribuição, o que resulta em ações excludentes por afastar agricultores que produzem localmente e romper com formas tradicionais de abastecimento, a fim de substituí-los por restritos e especializados fornecedores. Para as organizações, resulta a monopolização e domínio do mercado; para os pequenos agricultores, a pobreza e falta de espaço para o comércio dos alimentos por eles produzidos; e já para economia, a falta de dinamismo econômico devido ao domínio e transferência de divisas para as centrais dos grandes supermercados.

\subsection{PROCEDÊNCIA DAS FRUTAS E HORTALIÇAS}

Quanto à origem das frutas e hortaliças dos espaços de alimentação comercial, dez dos 17 estabelecimentos entrevistados $(58,2 \%)$ relatam adquirir todos ou quase todos os alimentos nos supermercados de Santiago. Resultados semelhantes foram encontrados em estudos com consumidores sobre a compra de hortifrutigranjeiros em hipermercados e feiras livres no município de Campinas (SP) desenvolvidos por Fonseca et al. (1999). Nesta pesquisa, os entrevistados citaram que a compra nos hipermercados tem como fatores determinantes a segurança pessoal, oferta de estacionamento e outros, ao invés de frescor e qualidade de produtos. A comodidade do consumidor que compra no supermercado também é buscada pelos espaços de alimentação comercial, já que ali podem fazer escolhas de acordo com suas necessidades, bem como ao que considera ser mais adequado na composição das refeições.

No fornecimento de frutas e hortaliças, destaca-se uma fruteira que fornece alimentos para cinco estabelecimentos de alimentação comercial (29,4\%). Partes das hortaliças folhosas desse local são produzidas e entregues diariamente por agricultores locais. Todavia, outros alimentos, como tubérculos e, principalmente as frutas, são provenientes de atacadistas especializados, os quais normalmente se abastecem na Central de Abastecimento do Estado do Rio Grande do Sul (CEASA-RS), e depois distribuem aos varejistas. Essa mesma forma de 
abastecimento se sucede na maioria dos supermercados e determina no dizer de Wiskerke (2009), que Santiago seja considerado um "ponto frio".

O provimento de alimentação nos pontos de alimentação comercial a partir da produção local de frutas e hortaliças foi identificado em sete estabelecimentos $(41,1 \%)$. A entrega direta dos alimentos pelo agricultor gera uma relação de confiança e de reciprocidade, conferindo regularidade nesse tipo de relação, dado pela pessoalidade da interação direta entre quem produz e quem consome. Para o agricultor, esse tipo venda reduz os custos de comercialização, como também os riscos de inadimplência, já que normalmente existe liquidez imediata pelo pagamento à vista. Já para os pontos de alimentação comercial, a compra direta proporciona a possibilidade de obtenção de produtos frescos, saudáveis e com uma vida útil maior, já que ele vai sendo utilizado de acordo com a necessidade.

A aquisição direta em feiras-livre acontece por cinco restaurantes $(29,4 \%)$, sendo que um deles frequenta permanentemente a feira de alimentos orgânicos, e quatro o Hortomercado Municipal. O município se caracteriza pela presença de três feiras livres que acontecem em locais diferentes, todos os dias da semana, à exceção de domingo: a Feira da Vila Nova, o Hortomercado Municipal e a Feira de Orgânicos. Nesses espaços, são comercializados alimentos produzidos exclusivamente por agricultores familiares. A aquisição de alimentos em feiras livres remete a maior frescor, naturalidade, procedência conhecida, e ainda, alimentos produzidos de forma mais sustentável (SILVA, 2008).

Entre os estabelecimentos comerciais, dois restaurantes são de uma mesma empresa, que possui produção própria de hortaliças e de alguns tipos de frutas, especialmente citros. A produção própria permite o conhecimento das condições em que os alimentos são produzidos, bem como em caso de excedentes, a comercialização direta para outros consumidores.

Quanto à aquisição realizada pelos espaços de alimentação coletiva, os quartéis obtém as frutas e as hortaliças de fornecedores especializados, principalmente do município de Santo Ângelo (RS) e também de fora do Estado. Por se tratar de um órgão vinculado a Administração Pública, a compra dos produtos se dava através de processos licitatórios. A alteração da compra por meio de chamada pública direta de quem produz os alimentos já vem causando impacto sobre a agricultura familiar do município. $\mathrm{Na}$ chamada pública realizada em agosto de 2016, destinada a aquisição de gêneros alimentícios para atender a demanda de consumo das Organizações Militares subordinadas ao Comando da $1^{\text {a }}$ Brigada de Cavalaria Mecanizada por um período de 10 meses foi previsto um valor total de R $\$ 573.508,88$. Já a segunda chamada pública, realizada em 13 de junho de 2017 , atingiu um total de R\$ 1.351.907,80. Trata-se de valores que destoam dos dados obtidos nas entrevistas com as unidades militares, pois incluem quantidades significativas de processados de origem vegetal e animal, além das frutas e hortaliças. Thies e Conterato (2017) também apontam positivamente a contribuição que o PAA vem proporcionando, porém no caso, analisando duas cooperativas da agricultura familiar no noroeste Gaúcho, que operam na modalidade de Compra com Doação Simultânea.

O Hospital de Caridade de Santiago mesmo que tenha área própria de produção de hortaliças, necessita que parte provenha do mercado convencional de alimentos, além da necessidade total das frutas. É percebido um distanciamento dos agricultores desse potencial de compra, mesmo sendo uma demanda organizada, centralizada e com capacidade de ser

DRd - Desenvolvimento Regional em debate (ISSNe 2237-9029) 
atendida pela produção local. Para o hospital a melhora na qualidade da oferta, permitiria um maior conhecimento em torno do que pode ser oferecido para seus pacientes.

O reconhecimento da qualidade superior do que é produzido nos municípios poderia, segundo Silva (2008), proporcionar um maior desenvolvimento regional, uma maior equidade social local e ainda mais, uma forma eficaz de agregar valor ao que é produzido no lugar. O caso de Santiago revela sinais de emergência de iniciativas que aproximam a produção local dos espaços de alimentação comercial e coletiva. A maioria dos estabelecimentos comerciais afirmou que o principal problema dessa produção é a qualidade e regularidade na oferta das hortaliças e das frutas. Se de um lado a produção de hortaliças tem o potencial de aumentar a produção e consequentemente essas formas de fornecimento dos alimentos, em termos de frutas a região está condicionada apenas a produção sazonal. O clima de Santiago não permite que a maior parte das frutas de consumo cotidiano seja produzida e as iniciativas acabam limitadas a algumas espécies de frutíferas em algumas épocas do ano. Isso não quer dizer que alguns agricultores não possam se especializar em determinados cultivos, como citros e outras frutíferas de clima temperado, a exemplo do pêssego, que o município mostra-se como um dos maiores produtores dessa fruta na Região Central (SILVA, 2016).

A comercialização pela proximidade ganha sentido como protagonista de uma forma de abastecimento alternativa na medida em que o alimento carrega consigo as informações em torno dele até chegar ao consumidor final. Apenas um espaço de alimentação comercial informa os tipos de alimentos utilizados para os consumidores. Em todos os demais não se tem nenhuma forma de comunicação capaz de aproximar e fortalecer os vínculos entre a oferta de produção com a demanda da alimentação fora de domicílio. Ou seja, mesmo com o alimento no território, a refeição é tomada simplesmente como um artefato da produção de mercadorias, relegada ao próprio mercado.

\section{CONSIDERAÇÕES FINAIS}

O município de Santiago possui uma população economicamente ativa expressiva, constituída ao longo de diversos processos formativos, nos quais se destaca a formação do efetivo militar, a viação férrea e a criação da universidade como marcos principais. Disso resulta a formação de um público expressivo de consumidores que realizam as refeições fora de domicílio. O número de refeições servidas, o valor gasto e a demanda por alimentos nos espaços de alimentação comercial e coletiva, produzem oportunidades para o setor produtivo, especialmente como pontos indutores para a dinamização socioeconômica, especialmente para a agricultura familiar.

Por mais que o abastecimento dos espaços de alimentação comercial seja dependente de fornecedores de outras regiões do estado, principalmente da CEASA-RS e atacadistas intermediários, verifica-se a emergência de iniciativas de abastecimento, em especial as feiras livres e a entrega direta dos agricultores aos espaços de alimentação comercial. Nos espaços de alimentação coletiva destaca-se o papel que as políticas públicas vêm tomando, especialmente o PAA, e que configuram uma demanda agregada significativa, e que vem ao encontro da necessidade de geração de trabalho e renda para a agricultura familiar. 
Do ponto de vista do tamanho dessas oportunidades, elas podem tomar uma expressão maior na medida em que reúnam conjuntamente outras formas de comercialização do município, tais como as feiras livres, as vendas diretas nos estabelecimento rurais, as entregas domiciliares, dentre outros. Mesmo diante das limitações apontadas no decorrer dos resultados, apresentam condições para configurar espaços de resistência ao sistema agroalimentar organizado através das cadeias convencionais. Isso gera um potencial para que a demanda proveniente das alimentações fora do domicílio possam compor o planejamento do abastecimento do município de outros adjacentes, o incremento nas áreas produtoras e a melhora da oferta de emprego à população rural. Assim, o desenvolvimento territorial passa pela indissociabilidade entre o rural e o urbano, em que pese a capacidade de que esses dois sujeitos devem ter em entender e tirar proveito das dinâmicas territoriais, que no caso da alimentação, está sustentado nos próprios recursos territoriais, mas também naqueles de fora, a exemplo da política pública do PAA. Avanços na articulação e regulação do fornecimento de alimentos para a alimentação comercial e coletiva podem trazer resultados promissores para o desenvolvimento do município

Estudos desta natureza são importantes para aprofundar o conhecimento sobre determinadas áreas econômicas que vem sendo relegadas ao "equilíbrio" do mercado, a exemplo do sistema agroalimentar. Indica-se para futuros estudos a possibilidade de compreender os critérios de decisão dos consumidores de espaços de alimentação comercial, em relação à origem dos alimentos que compõem suas refeições fora de domicílio.

\section{REFERÊNCIAS}

ASSOCIAÇÃO BRASILEIRA DAS INDÚSTRIAS DA ALIMENTAÇÃO (ABIA). Mercado de Food Service. 2015. Disponível em: <http://www.abia.org.br/cfs2015/ mercado.aspx>. Acesso em: 15 mar. 2016.

ASSOCIAÇÃO BRASILEIRA DE BARES E RESTAURANTES (ABRASEL). Disponível em: <http://www.abrasel.com.br>. Acesso em: 15 mar. 2016.

BEZERRA, I. N. et al. Consumo de alimentos fora do domicílio no Brasil. Revista Saúde Pública. v. 47, 2013. p. 200-211.

CLARO, R. M., LEVY R. B., BANDONI, D. H. Influência da renda sobre as despesas com alimentação fora do domicílio, no Brasil, 2002-2003. Cadernos de Saúde Pública (ENSP. Impresso). v. 25, p. 2489-2496, 2009.

CONSTANTINO, N. S. Santiago-RS: da concepção à maturidade em compasso brasileiro. Santiago/RS: Martins Livreiro-Editor, 1984.

DANELON, M. S. Riscos percebidos pelo consumidor e estratégias para minimizá-los no consumo de saladas de hortaliças cruas em restaurantes à la carte. 2012. 191f. Tese (Doutorado) - Faculdade de Engenharia de Alimentos, Universidade Estadual de Campinas, Campinas, 2012. 
DALLABRIDA, V. R. Governança territorial: do debate teórico à sua avaliação prática. Análise Social, v. 215, n. 50 (2), p. 304-328, 2015.

DUPUIS, E. M.; GOODMAN, D. Should we go "home" to eat?: toward a reflexive politics of localism. Journal of Rural Studies, v. 21, n. 3, p. 359-371, 2005. Disponível em: $<$ http://linkinghub.elsevier.com/retrieve/pii/S074301670500046X>. Acesso em: 02 abr 2016.

FAVERO, L. A. Novas formas de coordenação das atividades de abastecimento nos mercados atacadistas de frutas e hortaliças da América Latina. In: CONGRESSO DA SOCIEDADE BRASILEIRA DE ECONOMIA E SOCIOLOGIA RURAL, 43., 2005, Ribeirão Preto, Anais ... Ribeirão Preto: SOBER, 2005.

FONSECA, M. C. P. et al. Atitude dos consumidores com relação à compra de hortifrutícolas em hipermercados e feiras livres na cidade de Campinas - SP. Cadernos de Ciência \& Tecnologia, Brasília, v. 16, n. 1, p. 87-113, jan/abr. 1999.

GREEN, R.; SCHALLER, B. La dimesion logistique de la rationalisation productive et commercial. Revista Agroalimentaria. n. 3. p. 1-16, Diciembre 1996.

GUANZIROLI, C. H. Desenvolvimento Territorial Rural no Brasil: uma polêmica. Rio de Janeiro: UFF/ECONOMIA, Março de 2008. (Texto para discussão, $\mathrm{n}^{0}$ 233).

HARNACK, L. J.; JEFFERY, R. W.; BOUTELLE, K. N. Temporal trends in energy intake in the United States: an ecologic perspective. The American journal of clinical nutrition, $v$. 71, n. 6, p. 1478-1484, 2000.

HOSPITAL DE GUARNIÇÃO DE SANTIAGO (HGuSt). Histórico. Disponível em: $<$ http://www.hgust.eb.mil.br/index.php/historico>. Acesso em: 05 mar. 2016.

INSTITUTO BRASILEIRO DE GEOGRAFIA E ESTATÍSTICA (IBGE). Censo Demográfico 2010. Disponível em: <http://www.ibge.gov.br/home/estatistica/ populacao/censo2010/> Acesso em: 12 mar. 2016.

Pesquisa de orçamentos familiares 2008-2009: despesas, rendimentos e condições de vida. Rio de Janeiro: IBGE, 2010.

Pesquisa de orçamentos familiares 2008-2009: análise de consumo alimentar pessoal Brasil. Rio de Janeiro: IBGE, 2011.

INTERNATIONAL POLICY CENTRE FOR INCLUSIVE GROWTH (IPC-IG). Demanda estruturada e pequenos agricultores no Brasil: o caso do PAA e PNAE. Brasília: IPC-IG, 2013. $40 \mathrm{p}$.

JORNAL EXPRESSO ILUSTRADO. Quanto custa comer em Santiago? Santiago/RS: Caderno de gastronomia, p.47, 24 jul. 2015.

LIMA-FILHO, D. O. et al. Impacto das informações nutricionais no comportamento do consumidor de restaurantes. Revvista Organizações Rurais \& Agroindustriais, Lavras, v. 16, n. 3, p. 404-416, 2014. 
MALUF, R. S. Ações públicas locais de abastecimento alimentar. 1999. Pólis Papers 5, 2009. Disponível em: <http://www.polis.org.br/uploads/845/845.pdf > . Acesso em: 29 abr. 2016.

MALUF, R. S. Mercados agroalimentares e a agricultura familiar no Brasil: agregação de valor, cadeias integradas e circuitos regionais. Ensaios FEE, Porto Alegre, v. 25, n. 1, p 299322, abr. 2004.

MARTINS, E. Fichas para MARC [mensagem pessoal]. Mensagem recebida por <gustavo.pinto@politecnico.ufsm.br>em 02 set. 2015.

MORGAN, K.; SONNINO, R. The urban foodscape: world cities and the new food equation. Cambridge Journal of Regions, Economy and Society, v. 3, n. 2, p. 209 - 224, 10 mar. 2010.

MORO, C. F. S. Números URI [mensagem pessoal]. Mensagem recebida por $<$ eduardodudutra@hotmail.com>.em 29 maio 2015.

PECQUEUR, B. A guinada territorial da economia global. Política e Sociedade, n. 14, p. 79105, abr. 2009.

PEREZ-CASSARINO, J.; FERREIRA, A. D. D. A construção de mecanismos alternativos de mercados de alimentos ecológicos como forma de redesenhar os sistemas agroalimentares: a proposta dos circuitos de proximidade. In: VI Congresso Internacional Sistemas Agroalimentares Localizados, 2013, Florianópolis-SC. Anais... Florianópolis: UFSC, 2013. v. 1.

POTHUKUCHI, K; KAUFMAN, J. L. Placing the food system on the urban agenda: The role of municipal institutions in food systems planning, Agriculture and Human Values. v. 16, n. 2, p.213-224, 1999.

REARDON, T. et al. The Rise of Supermarkets in Africa, Asia and Latin America. American Journal of Agricultural Economics, v. 5, n. 85, p. 1140-1146, 2003.

SCARABELOT, M. Construção de cadeias agroalimentares curtas e papel dos atores em Nova Veneza, SC. 201f. Dissertação (mestrado) - Faculdade de Ciências Econômicas, Universidade Federal do Rio Grande do Sul, Porto Alegre, 2012.

SCHMITT, C. J. Encurtando o caminho entre a produção e o consumo de alimentos. Revista Agriculturas, v. 8, n. 5, p. 4-8, set. de 2011.

SCHNEIDER, S.; FERRARI, D. L. Cadeias curtas, cooperação e produtos de qualidade na agricultura familiar: o processo de relocalização da produção agroalimentar em Santa Catarina. Revista Organizações Rurais \& Agroindustriais, Lavras, v. 17, n. 1, p. 56-71, 2015.

SILVA, C. A. Dinâmica e estratégias em circuitos alimentares de proximidade. In: IV ENEC - Encontro Nacional de Estudos do Consumo, 2008, Rio de Janeiro. Anais... Rio de Janeiro: ENEC, 2008. 
SILVA, G. P. A construção social dos circuitos curtos de comercialização e consumo de alimentos: a emergência de novas institucionalidades. 2016. 273 p. Tese (Doutorado em Extensão Rural) - Universidade Federal de Santa Maria, Santa Maria/RS, 2016.

SIMÕES, A. A. Santiago, sua terra, sua gente: Rio Grande do Sul. Porto Alegre: Martins Livreiro, 1989. 196p.

SOUSA, A. A. Perfil do consumidor de alimentos orientado para saúde no Brasil. 2006. 187f. Dissertação (Mestrado) - Programa de Pós-Graduação Multi-institucional em Agronegócios. Consórcio entre Universidade Federal de Mato Grosso do Sul, Universidade de Brasília, Universidade Federal de Goiás. Campo Grande-MS. 31 out. 2006.

SUMPSI, J. M. Desarollo rural con enfoque territorial: diferencias y semejanzas de las experiencias de La Unión Europea y America Latina. In: ORTEGA, A. C.; ALMEIDA FILHO, N. (Org.). Desenvolvimento territorial, segurança alimentar e economia solidária. Campinas: Alínea, 2007. v. 1, p. 63-91.

THIES, V. F.; CONTERATO, M. A. Agricultura familiar e autonomia: a construção social e política de mercados no noroeste gaúcho. Desenvolvimento Regional em debate, Canoinhas, SC, v. 7, n. 1, p. 51-74, maio 2017.

TRICHES, R. M. Reconectando a produção ao consumo: a aquisição de gêneros alimentícios da agricultura familiar para o Programa de Alimentação Escolar. 2010. $296 f$. Tese (Doutorado) - Faculdade de Ciências Econômicas. Porto Alegre, 2010.

VEIGA, J. E. A face territorial do desenvolvimento. Revista Internacional de Desenvolvimento Local, v. 3, n. 5, p. 5 - 19, 2002.

VIDAL, G. M. et al. Avaliação das boas práticas em segurança alimentar de uma unidade de alimentação e nutrição de uma organização militar da cidade de Belém, Pará. Alimentos e Nutrição Araraquara, v. 22, n. 2, p. 283-290, abr./jun. 2011.

WILKINSON, J. A Agricultura Familiar ante o Novo Padrão de Competitividade do Sistema Agroalimentar na América Latina. Estudos Sociedade e Agricultura, Rio de Janeiro, v. 1, n.21, p. 62-87, 2004.

WISKERKE, J. S. C. On Places Lost and Places Regained: Reflections on the Alternative Food Geography and Sustainable Regional Development. International Planning Studies, v. 14 , n. 4 , p. $369-387,2009$.

Artigo recebido em: 25/04/2017

Artigo aprovado em: 10/08/2017 